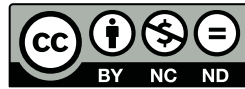

Estudos Teológicos foi licenciado com uma Licença Creative Commons Atribuição - NãoComercial - SemDerivados 3.0 Não Adaptada

http://dx.doi.org/10.22351/et.v.57i2.2610

\title{
A OPÇÃo PREFERENCIAL PElos POBRES À LUZ DA TEOlOGia dA LIBERTAÇÃO: UMA RELEITURA LASSALISTA ${ }^{1}$
}

The preferential option for the poor in the light of liberation theology: a Lasallian rereading

\section{Taylon de Amorim Torres ${ }^{2}$ Evaldo Luis Pauly ${ }^{3}$}

\begin{abstract}
Resumo: Este artigo interpreta a concepção teológica da opção preferencial pelos pobres formulada por Gustavo Gutiérrez a partir de uma perspectiva lassalista. Para tanto, tenta demonstrar algumas relações entre a teologia da libertação (TdL) e a pedagogia lassalista, tendo como critério a emancipação dos pobres na América Latina. Inicialmente, o artigo analisa o surgimento da TdL no contexto social latino-americano de luta contra a pobreza nas quatro últimas décadas do século XX. Na sequência, analisa o novo contexto de enfrentamento da pobreza nas duas primeiras décadas do século XXI no Brasil; para concluir que, mesmo havendo uma mudança qualitativa recente na realidade da pobreza, ainda é pertinente e necessária a opção pelos pobres defendida tanto pela TdL como pela pedagogia lassalista.
\end{abstract}

Palavras-chave: Opção pelos pobres. La Salle. Teologia da libertação. Serviço educativo a pobres. Pedagogia lassalista.

Abstract: This article interprets the theological conception of the preferential option for the poor formulated by Gustavo Gutiérrez, From a Lasallian perspective. To this end, tries to demonstrate some relationships between Liberation Theology (TdL) and Lasallian pedagogy, having as criterion the emancipation of the poor in Latin America. Initially, the article analyzes the emergence of liberation theology in Latin American social context of combating poverty in the last four decades of the twentieth century. Then, it analyzes the new context of struggle against poverty in the first two decades

1 O artigo foi recebido em 27 de novembro de 2015 e aprovado em 13 de junho de 2017 com base nas avaliações dos pareceristas ad hoc.

2 Graduação em Teologia pelo Universidade La Salle - Unilasalle - Canoas/RS (2016). Irmão Lassalista e professor do Colégio La Salle, Toledo/PR, Brasil. Contato: taylon.torres@lasalle.org.br

3 Doutor em Educação pela Universidade Federal do Rio Grande do Sul - UFRGS (2000). Docente do Programa de Pós-Graduação em Educação - Mestrado e Doutorado, da Universidade La Salle - UNILASALLE, Canoas/RS, Brasil. Contato: evaldo@unilasalle.edu.br 
of the twenty-first century in Brazil; it concludes that, the option for the poor is still a relevant and necessary option supported both by liberation theology as the Lasallian Pedagogy.

Keywords: Option for the poor. La Salle. Liberation theology. Educational service of the poor. Lasallian pedagogy.

\section{Introdução}

No século XVII, um pequeno grupo de professores de crianças, liderado por João Batista de La Salle, doutor em Teologia pela Sorbonne, estava convicto de que Deus desejava oferecer educação às crianças pobres. Assim motivado, esse grupo fundou o Instituto dos Irmãos das Escolas Cristãs em 1684, assumindo a vida consagrada, a condição de professores leigos num contexto cultural de cristandade que valorizava mais os clérigos que os leigos. Organizaram uma rede de escolas gratuitas através das quais pretendiam oferecer a salvação cristã para as crianças pobres através da educação elementar. Sob o regime aristocrático e absolutista do rei Sol, Luis XIV, a visão religiosa da educação de La Salle e seus primeiros professores implicava uma educação capaz de propiciar inserção social qualificada dos pobres em função do aprendizado profissional desenvolvido pela escola cristã. Para tanto, La Salle formulou as "Regras Comuns dos Irmãos das Escolas Cristãs", que foram aprovadas no primeiro capítulo geral dessa ordem religiosa católica. Na versão de 1717, a primeira regra determinou que suas escolas seriam gratuitas, sendo atendidas por professores cristãos de vida consagrada à educação cristã e escolar dos filhos de artesãos e pobres, pois, segundo a análise dos primeiros irmãos, seu instituto seria

de grandíssima necessidade, porquanto, sendo os artesãos e os pobres ordinariamente pouco instruídos, estando ocupados todo o dia em ganhar o sustento próprio e dos filhos, não lhes podem dar, por si mesmos, as instruções de que necessitam e educação adequada e cristã ${ }^{4}$.

Para Gauthier e Tardif, o Guia das Escolas Cristãs e outros "tratados de pedagogia do século XVII nos parecem fundadores. Eles inauguram o método de ensino nas escolas" da educação elementar e "são concebidos para definir as ações do mestre no seu ensino a grupos de filhos do povo", portanto criam a "tradição pedagógica" chamada de "pedagogia tradicional", que "será exportada para a América"5, moldando historicamente as escolas destinadas à universalização da educação primária moderna. Na visão de Hengemüle, La Salle, concretamente

4 LA SALLE, São João Batista de. Regras Comuns dos Irmãos das escolas Cristãs. In: . Obras Completas. Canoas: Unilasalle, 2012. v. II-A, p. 18.

5 GAUTHIER, Clermont; TARDIF, Maurice. A Pedagogia: teorias e práticas da Antiguidade aos nossos dias. Petrópolis: Vozes, 2010. p. 146-147. 
optou por clientela popular, foi ao encontro dela, ofereceu-lhe consideração e amor preferentes, criou escolas e programas à sua medida, contribuiu à criação de uma cultura popular, preparou mestres populares, e fez sua escola exercer a função social de promover os pobres ${ }^{6}$.

No século XX, a TdL surge na América Latina colocando os pobres no centro de sua reflexão e práxis pastoral, tornando-se quase um sinônimo de teologia latino-americana. No século XXI, já sob a consolidação dos regimes democráticos no continente, a preocupação teológica com os pobres permanece atual nessa teologia. ${ }^{7}$ Atualmente, os educadores lassalistas da América Latina empreendem uma aproximação entre a pedagogia cristã de La Salle, centrada nas crianças francesas pobres do século XVII, e a teologia da libertação, voltada ao povo pobre latino-americano. ${ }^{8}$ Cabe, portanto, refletir acerca das razões de ser um educador lassalista nos sistemas educacionais mantidos pelos regimes democráticos na América Latina do século XXI. A ciência política define regime democrático pela constituição republicana, no entanto, como se impressionou Przeworski, houve uma "obsessão da América Latina com o constitucionalismo: a primeira coisa que muitos 'caudillos', 'homens fortes', 'ditadores' ou 'autocratas' faziam no palácio presidencial era promulgar uma nova Constituição" . Como, afinal, os lassalistas latino-americanos traduzem, para seu contexto educacional, a experiência pedagógica de La Salle mais de trezentos anos depois da fundação do Instituto dos Irmãos das Escolas Cristãs na França aristocrática e pré-revolucionária? Para enfrentar essa questão, o artigo inicia com uma análise do surgimento da TdL, seja no contexto das pastorais que enfrentaram a pobreza no final do século XX seja no novo contexto político dos primeiros anos do século XXI no Brasil. Apesar das mudanças na realidade da pobreza, a opção pelos pobres defendida tanto pela TdL como pela pedagogia lassalista permanece pertinente.

\section{O surgimento da teologia da libertação}

Segundo Boff, “a Teologia da Libertação nasceu ouvindo o grito do oprimido. Seu mérito foi ter dado centralidade ao empobrecido, fazendo-o sujeito de sua história" ${ }^{10}$. Os bispos, reunidos na Terceira Conferência do Episcopado Latino-Americano em Puebla, em 1979, fazem uma opção, mas não uma opção qualquer, uma opção pela libertação contra a pobreza.

\footnotetext{
HENGEMÜLE, Edgard. Educação Lassaliana: Que Educação? Canoas: Unilasalle, 2007. p. 61.

ALBUQUERQUE, Francisco das Chagas de. Teologia da Libertação na pós-modernidade: contribuição à humanização. Perspectiva Teológica, Belo Horizonte, v. 48, n. 2, p. 289-316, 2016.

8 MUÑOZ LEÓN, Diego A. Cómo los lasalianos comprenden la asociación desde su experiencia personal: estudio de testimonios de hermanos y laicos de la RELAL. Revista Digital de Investigación Lasaliana, Roma, n. 1, p. 51-64, 2010.

9 PRZEWORSKI, Adam. A mecânica da instabilidade de regime na América Latina. Novos Estudos - CEBRAP, São Paulo, v. 100, p. 27-54, 2014. p. 31.

${ }^{10}$ SUSIN, Luiz Carlos (Org.). Teologia para outro mundo possivel. São Paulo: Paulinas, 2006. p. 239.
} 
“Opção" quer dizer decisão, tomada de partido. Entre opressores e oprimidos (no caso latino-americano), a Igreja toma o partido dos últimos. Trata-se de uma decisão política (pois os pobres são fruto de uma estrutura sócio-política opressora), ética (é um imperativo moral) e evangélica (pois essa foi a opção de Jesus). ${ }^{11}$

A TdL é um movimento socioeclesial que brotou na década de 1960 dentro da Igreja Católica e de outras denominações cristãs na América Latina.

Esse movimento envolveu setores significativos da Igreja (padres, ordens religiosas, bispos), movimentos religiosos laicos (Ação Católica, Juventude Universitária Cristã, Juventude Operária Cristã) redes pastorais com base popular, comunidades eclesiais de base (CEBs), bem como várias organizações populares criadas por ativistas das CEBS, clubes de mulheres, associações de moradores, sindicados de camponeses ou trabalhadores, etc. ${ }^{12}$

A partir desses movimentos, podemos compreender a abrangência e a força da TdL, ou simplesmente podemos dizer: a América Latina não é mais a mesma. A TdL foi muito além do campo religioso; ultrapassou as instituições religiosas. Esse movimento mobilizou e revolucionou a igreja, a política e a sociedade ao redor de um bem comum: um "cristianismo libertador"13.

Para Löwy, na época, “o Cristianismo da Libertação é combatido fortemente pelo Vaticano e pelo órgão regulamentador da hierarquia da Igreja na América Latina"14. Será que podemos, de certa forma, afirmar que dentro da Igreja Católica Apostólica Romana havia uma resistência contra a TdL? Embora, as respostas para essa questão possam ser divergentes, permanece, no entanto, o fato de que a "hierarquia católica assumiu e reconheceu o que identificou de melhor nessa teologia, que por sinal são fatores fundamentais: a opção preferencial pelos pobres, a dimensão sociolibertadora da fé e a constituição das Comunidades Eclesiais de Base"15. Assim a TdL permanece antes de tudo como um discurso religioso e teológico que transita no âmbito eclesial, social e político.

A primeira tarefa da Igreja é celebrar, com alegria, a dádiva da ação redentora de Deus na humanidade, que realizou-se através da morte e ressurreição de Cristo. É a Eucaristia, memorial e ação de graças. Memorial para Cristo que supõe uma aceitação sempre renovada do significado da vida: a dádiva total para os demais. ${ }^{16}$

11 Documento de Puebla. Texto Oficial Puebla de Los Angeles, México, 27-1 a 13-2 de 1979. São Paulo: Paulinas.

${ }^{12}$ LÖWY, Michael. Guerra dos deuses: religião e política na América Latina. Petrópolis: Vozes, 2000. p. 56.

13 LÖWY, 2000, p. 140.

14 LÖWY, 2000, p. 58.

15 ALBUQUERQUE, 2016, p. 302.

${ }^{16}$ GUTIÉRREZ, Gustavo. Teologia da libertação-Perspectivas. São Paulo: Loyola, 2000. p. 261. 
Para resumir essa afirmação, pode-se usar a expressão da Conferência dos Bispos Latino-Americanos de Puebla (1979): "a opção preferencial pelos pobres". Sem dúvida, essa declaração que os bispos dão em Puebla é também a ideia central da TdL. "Os pobres são os agentes de sua própria libertação e o sujeito de sua própria história", ou seja, para os bispos, os pobres são promotores e construtores da "dádiva total para os demais"'17.

\section{Contexto da teologia da libertação}

Gustavo Gutiérrez é um dos principais expoentes da teologia da libertação. A seu modo, engajou-se na luta pelas massas pobres, que não tinham voz e vez na América Latina. Utilizou-se da teologia como instrumento que lhe permitia fazer uma análise crítica da sociedade latino-americana e, assim, reestruturar a Igreja Católica a partir de uma práxis afirmativa de que o reino de Deus já se estava fazendo valer na América Latina, especialmente entre os oprimidos. Para Gutiérrez, a teologia utilizada dentro da Igreja Católica era insuficiente. Era preciso tomar a atitude de ouvir o outro.

É necessário colocar-se numa atitude de ouvir e ouvir pressupõe antes de mais nada sair do pequeno mundo em que se está. A comunidade cristã da América Latina tem vivido e continua vivendo em grande parte num estado de gueto. Surgindo quando a Igreja-mãe se encontrava à frente da Contra-Reforma, a Igreja latino-americana ficou marcada por uma atitude de defesa. ${ }^{18}$

A TdL inicia uma nova corrente teológica na América Latina. Ela nasce logo depois de dois momentos históricos impactantes para a Igreja Católica na América Latina: o Concílio Vaticano II e a Conferência de Medellín (Colômbia, 1968). "Medellín não vacila em falar de "violência institucionalizada" 19 praticada pelos regimes ditatoriais então vigentes na maioria dos países da América Latina e de denunciá-la profeticamente.

Estamos diante de um momento de crise eclesial. Gutiérrez diz que a Igreja Católica "resolvia as dificuldades e interrogações que lhe colocavam apelando imperturbavelmente para as reservas doutrinais e vitais. Agora, porém, é a Igreja mesma que está em causa" 20 . É necessário que a igreja dê uma resposta e "acalme" o seu interior e exterior; é preciso encarar os clamores de um povo que quer libertação:

Até a década de 1960, a Igreja na América Latina não tinha nem rosto e nem palavra própria. O rosto lhe foi dado pelas práticas dos cristãos em perspectiva libertadora, nas

${ }^{17}$ LÖWY, 2000, p. 60.

${ }_{18}$ GUTIÉRREZ, Gustavo. A força histórica dos pobres. Petrópolis: Vozes, 1981. p. 44-45.

19 GUTIÉRREZ, 1981, p. 45.

${ }^{20}$ GUTIÉRREZ, 1981, p. 41. 
Comunidades Eclesiais de Base, na Leitura Popular da Bíblia, na Pastoral Social e pelo testemunho dos mártires das causas sociais, como Dom Romero e Irmã Dorothy ${ }^{21}$.

Para Gutiérrez, "a mudança mais importante no conhecimento da realidade latino-americana diz respeito a suas causas mais profundas, vistas na perspectiva de um processo histórico" 22 . Seriam resultados da "dependência econômica, política e cultural do centro de poder que estão fora da América Latina"23. O povo latino-americano espera uma igreja que leve em frente uma nova evangelização para o continente. Só com ela entenderemos a solicitação do papa Francisco quando diz: "desejo uma Igreja pobre para os pobres"24.

O que estava por trás da TdL, para Leonardo Boff e Clodovis Boff, era a percepção da realidade sofrida do pobre e injustiçado.

A percepção da realidade é escandalosa [...] que existem não só na América Latina, mas em escala mundial por todo o Terceiro Mundo. Existem nos países mantidos no subdesenvolvimento: 500 milhões de famintos; 1 bilhão e setecentos milhões com esperança de vida inferior a 60 anos; 1 bilhão de pessoas padecem pobreza absoluta; 1 bilhão e quinhentos milhões não tem acesso ao mínimo atendimento médico; 500 milhões são desempregados e subempregados com uma renda per capita inferior a 150 dólares; 814 milhões são analfabetos; 2 bilhões carecem de fontes seguras e estáveis de água, conforme cálculos "conservadores". ${ }^{25}$

Podemos dizer que todas as boas teologias nasceram e nascem de uma percepção da realidade à luz da fé na qual elas surgem. Assim, "toda verdadeira teologia nasce de uma espiritualidade, [...] de um encontro forte com Deus dentro da história" ${ }^{26}$. A América Latina, nesse período que estamos considerando, estava tomada pelas ditaduras, pela pobreza e pela falta de esperança e, ao mesmo tempo, por uma força gigante em busca de liberdade. Na visão de Gutiérrez, "o Concílio Vaticano II afirma que a Igreja, como Cristo, deve realizar sua obra de redenção 'em pobreza e perseguição" "27. O povo quer concretizar o projeto do reino de Deus. A TdL não nasceu simplesmente como uma teoria, mas como uma "teoria orientada para a prática e da prática".

A TdL precisou ir mais longe. Foi, antes de tudo, uma libertação da teologia dos moldes europeus. Fato é que a TdL não abandonou o caráter cristocêntrico; nasceu de uma análise concreta feita a partir dos pobres, com caráter cristão, tendo como referencial central a prática de Jesus Cristo.

\footnotetext{
${ }^{21}$ BRIGHENTI apud GUTIÉRREZ, Gustavo; MÜLLER, Gerhard Ludwig. Ao lado dos pobres: Teologia da Libertação. São Paulo: Paulinas, 2014. p. 12.

22 GUTIÉRREZ, 1981, p. 46.

${ }^{23}$ GUTIÉRREZ, 1981, p. 46.

${ }^{24}$ FRANCISCO, Papa. Exortação Apostólica Evangelii Gaudium. São Paulo: Paulinas, 2013. p. 165.

${ }_{25}$ BOFF, Leonardo; BOFF, Clodovis. Como fazer Teologia da Libertação. Petrópolis: Vozes, 1986. p. 12-13.

${ }^{26}$ BOFF; BOFF, 1986, p. 14.

27 GUTIÉRREZ, 1981, p. 49.
} 
A opressão contra os pobres sempre foi um estado escandaloso ao longo dos séculos. A dignidade humana é colocada em jogo. Para C. Boff, "as dores e esperanças dos pobres são também as dores e esperanças da Igreja deste continente". Por isso a igreja tem que ouvir o clamor dos pobres e ajudá-los na busca por mais dignidade. Segundo C. Boff, 'a Igreja cristã, por ser a portadora da 'memória de Jesus', é também portadora da 'memória dos pobres'. Ela é ‘vigária de Cristo’ e, em virtude disso ‘vigária dos pobres"' 28 . E isso não apenas por uma primazia pastoral, mas por um mandado evangélico. É notório que a TdL sempre buscou colocar a igreja "ao lado dos pobres" na luta pela mudança social. Em função dessa busca, a TdL, por vezes, adotou um tom mais sociológico e político que evangélico, essa seria

a acusação de fundo. A TdL e todo o movimento eclesial do qual ela faz parte teria perdido o sentido evangélico libertador; [...]. Enfim, o movimento teológico e pastoral nascido no hemisfério sul teria se afastado do evangelho. A libertação refletida nessa conjuntura seria simplesmente a libertação material, temporal e histórica. Tais críticas provinham tanto de fora quanto de dentro do âmbito eclesial. Os embates e os debates que aconteceram nesse processo resultaram, finalmente, não sem reservas de alguns membros da Igreja, em ganho para a Igreja não só do continente, mas também para a Igreja em nível mundial ${ }^{29}$.

Como diz o teólogo, "queremos ter o ouvido e o coração de nosso Deus para ouvir o "clamor de aflição dos pobres"" 30 . É nessa posição que estaremos onde Deus está. "Por detrás da TdL existe a opção profética e solidária com a vida, a causa e as lutas destes milhões de humilhados e ofendidos em vista da superação desta iniquidade histórico-social" ${ }^{31}$. O clamor dos pobres também demarcou a intuição fundacional da educação lassalista:

La Salle se dá conta de que para garantir o sucesso das escolas e a educação dos filhos dos artesãos e dos pobres teria que formar uma comunidade de mestres comprometidos por inteiro com o magistério, totalmente entregues à escola e às crianças das quais estão encarregados pelo próprio Deus, na sua concepção religiosa. Por isso La Salle quer educadores que sejam professores com formação e dedicação exclusivas ao Magistério, não assumindo nenhuma função eclesiástica como sacerdotes ou assistentes do pároco $^{32}$.

${ }^{28}$ BOFF, Clodovis. A opção preferencial pelos excluídos. In: BEOZZO, José Oscar et al. Vida, clamor e esperança: reflexões para os 500 anos de evangelização a partir da América Latina. São Paulo: Loyola, 1992. p. 327.

29 ALBUQUERQUE, 2016, p. 297-298.

30 BOFF, 1992, p. 327.

31 BOFF, 1986, p. 13-14.

${ }^{32}$ LEUBET, Ângelo Ezequiel; PAULY, Evaldo Luis; SILVA, Valdir Leonardo da. Contribuições de João Batista de La Salle para a constituição da escola moderna. Revista Brasileira de História da Educação, Maringá-PR, v. 16, n. 4 [43], 2016. p. 32-63. 


\section{O conceito de pobreza no Brasil contemporâneo: de 2000 a 2015}

Gutiérrez entende que a "pobreza constituiu um dos temas centrais da espiritualidade cristã contemporânea" ${ }^{33}$ e que, mesmo assim, esse termo pode causar algum "equívoco". Para evitar equívocos, este item analisa algumas definições do fenômeno da pobreza e a ampliação da compreensão sociológica de pobreza. Definido o conceito de pobreza, o artigo desenvolve uma compreensão analítica sobre a educação cristã dos pobres na perspectiva lassalista, que visa à libertação das condições de pobreza mediante uma educação de qualidade humana e cristã, bem como de preparação para o mundo do trabalho. Ao compreender a complexidade do fenômeno da pobreza e seus diferentes conceitos e abordagens, torna-se possível entender muitos dos esforços pastorais da TdL na América Latina.

A conceituação de pobreza é categorizada como “juízo de valor” quando se trata de uma visão subjetiva, abstrata, do indivíduo, acerca do que deveria ser um grau suficiente de satisfação de necessidades, ou do que deveria ser um nível de privação normalmente suportável. O indivíduo expressa sentimentos e receitas, de caráter basicamente normativo, do que deveriam ser os padrões contemporâneos da sociedade quanto à pobreza. Não leva em conta uma situação social concreta, objetivamente identificável, caracterizada pela falta de recursos. Desse modo, tal enfoque não esconde sua fragilidade, embora seja bastante óbvio que mesmo uma conceituação objetiva da pobreza não se furta à presença de algum juízo de valor. ${ }^{34}$

No Vaticano II, a igreja se perguntava em que mundo ela deveria se inserir, "dentro do mundo dos $20 \%$ de incluídos ou do mundo dos $80 \%$ de excluídos? Do mundo dos $20 \%$ da população que consomem $80 \%$ dos recursos do planeta ou do mundo dos $80 \%$ de excluídos que só têm acesso a $20 \%$ deles" ${ }^{35}$. Segundo Boff, "os $20 \%$ mais ricos da população mundial consomem $93 \%$ de todos os produtos e serviços, enquanto os $20 \%$ mais pobres consomem apenas $1,4 \%{ }^{" 36}$. Sem dúvida, há uma exploração do homem pelo outro homem. São dramáticos os dados sobre a injustiça e a má distribuição dos recursos, particularmente, no Brasil:

os $10 \%$ mais ricos concentram $50 \%$ da riqueza nacional; os $50 \%$ mais pobres detêm apenas $10 \% ; 40 \%$ da população brasileira vive abaixo da linha de pobreza; e cinquenta milhões de brasileiros não conseguem ter uma alimentação suficiente ${ }^{37}$.

Esses dados podem ser apresentados de outro modo:

\footnotetext{
${ }^{33}$ GUTIÉRREZ, Gustavo. Teologia da Libertação - perspectivas. Petrópolis: Vozes, 1975. p. 235.

${ }^{34}$ CRESPO, Antônio Pedro Albernaz; GUROVITZ, Elaine. A pobreza como um fenômeno multidimensional. RAE-eletrônica, São Paulo, v. 1, n. 2, p. 1-12, 2002. p. 3.

${ }^{35}$ GUTIÉRREZ; MÜLLER, 2014, p. 09.

${ }^{36}$ BOFF, Leonardo. Experimentar Deus: a transparência de todas as coisas. 2. ed. Petrópolis: Vozes, 2012. p. 59.

${ }^{37}$ BOFF, 2012, p. 60.
} 
Não obstante o crescimento da renda ter sido maior para os décimos mais pobres, as diferenças de renda entre as famílias permaneceram muito elevadas: o rendimento dos $40 \%$ mais pobres foi de $\mathrm{R} \$ 241,81$ per capita, enquanto os $5 \%$ mais ricos tiveram um

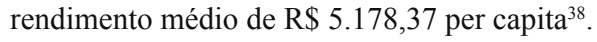

O que podemos considerar hoje como pobreza? O que é ser pobre? Será que ser pobre é não ter muito dinheiro? Será que ser pobre é ter rendimento médio 21 vezes menor do que o rendimento médio dos ricos? Podemos dizer que o termo pobreza vai além de simplesmente não ter dinheiro? É importante salientar que estar no estado de pobreza é, certamente, experimentar na pele a não dignidade humana. É claro que a dignidade humana não se reduz à posse de determinada quantia de dinheiro, como já dizia o apóstolo Paulo sobre a dimensão moral da dignidade humana: "não faço o bem que quero, mas pratico o mal que não quero" 39 . A pessoa humana não é carente apenas de dinheiro, dele necessita, mas para viver condignamente, existem outras carências culturais e sociais que remetem, por exemplo, para esta outra passagem bíblica: "e o homem deu nomes a todos os animais, às aves do céu e a todas as feras selvagens, mas, para o homem, não encontrou a auxiliar que lhe correspondesse" ${ }^{40}$. Para além das necessidades econômicas, a vida humana digna implica relações mais harmônicas com a natureza e mais afetuosas com outras pessoas para superar o ensimesmamento, pois o ser humano, desde a sua origem, experimenta "o amargo sabor do egoísmo"41 alimentado pela ganância de ter cada vez mais. O mundo globalizado está demandando postura mais firme e apostólica das práticas educativas inspiradas na fé cristã.

Podemos dizer que, ao longo da história humana, os pobres vêm sofrendo perdas dos seus “direitos”. Quem são os pobres? "É pobre, portanto, quem carece dos meios de vida. Quem não tem os meios materiais para viver nem para se desenvolver com dignidade no plano social, político e cultural." ${ }^{42}$ Os direitos básicos, como ter uma vida digna e justa, são tirados dos pobres com muita facilidade na América Latina.

A pobreza também pode ser caraterizada e aceita, de forma equivocada ou acrítica, como uma predeterminação da divindade ou dos deuses. Esse tipo de compreensão religiosa aceita que alguém que tenha nascido pobre deva continuar pobre porque essa é uma forma de obedecer ao desígnio divino. No caso do Brasil, os pobres são tratados, de certa forma, como se vivêssemos em um sistema de castas. "O Brasil foi um país de escravos. Tivemos três séculos e meio de regime escravocrata, contra apenas um de trabalho livre. Ao longo desses três séculos e meio importamos 4 milhões de negros africanos" ${ }^{\prime 4}$. Ao longo da história, a concepção de trabalho mal remunerado foi passada de geração em geração, criando-se uma espécie de senso comum de que

38 IPEA. Instituto de Pesquisa Econômica Aplicada. Duas décadas de desigualdade e pobreza no Brasil medidas pela Pnad/IBGE. Comunicados do Ipea, Brasília, n. 159, 01 de outubro de 2013, p. 9.

39 Romanos 7.19

40 Gênesis 2.20.

41 BETTO, Frei. Fome de Deus. São Paulo: Paralela, 2013. p. 63.

42 ALDUNATE, José et al. Direitos humanos, direitos dos pobres. São Paulo: Paulinas, 1990. p. 16.

43 NORT, Egon. Brasil rumo ao primeiro mundo. Florianópolis: Edição do autor, 1997. p. 381. 
é admissível tratar as pessoas como mercadoria. Outro indicador estatístico aponta que, a partir

do Plano Brasil Sem Miséria (BSM), ajustada pelo INPC, a extrema pobreza diminuiu de $13,7 \%$ para $3,6 \%$ entre 1992 e 2012 , enquanto a pobreza foi de $31,5 \%$ para $8 \%$. Foram menos de 12 milhões de pessoas vivendo na miséria e menos 28 milhões de pessoas vivendo na pobreza. Esse movimento de queda da pobreza ocorreu inclusive em 2012: nesse último ano da Pnad, foram menos 3,5 milhões de pessoas na pobreza e menos 1 milhão de pessoas na extrema pobreza $[\ldots]^{44}$.

Os economistas afirmam que "se a população for dividida em frações menores, é possível observar que a renda dos $5 \%$ mais ricos cresceu $9,4 \%$ e a do $1 \%$ mais rico cresceu $16,1 \%$, mas, ao mesmo tempo, a dos $5 \%$ mais pobres cresceu $20 \% " 45$. Houve uma diminuição da pobreza no Brasil, uma queda pequena, mas significativa. Esse fato demonstra que é possível, sem grandes transformações sociais, reduzir a pobreza, ou seja, permitir que milhões de pessoas melhorem suas condições de vida. Se de um lado, "entre os 12\% mais ricos, a desigualdade subiu em 2012", por outro "a proporção de pessoas abaixo da linha oficial de extrema pobreza (R $\$ 70$ per capita em julho de 2011) corrigida pela inflação caiu de 4,2\% em 2011 para 3,6\% em 2012, quando 6,5 milhões de pessoas viviam nessa situação"46.

Essa redistribuição de renda, para o IPEA, não se deve apenas aos programas de transferência de renda, pois há "clara correlação positiva entre maior escolaridade e maior rendimento. [...] Desde 1992, pode-se perceber grande melhora educacional ao longo de toda a distribuição, em especial entre os mais pobres" ${ }^{\prime 7}$. Por outro lado, a pobreza gera desigualdade. No Brasil atual desenvolvem-se políticas para reduzir a pobreza extrema, mas ainda permanece um índice alarmante de pobreza. Segundo Yannoulas e outros, "algumas das ações e programas para atendimento dessas necessidades sociais, como vacinação, merenda escolar, material escolar, uniforme etc., são aplicadas de forma genérica ou universal" ${ }^{48}$. Pobreza e desigualdade são obras humanas, por isso podem ser desconstruídas.

\section{A opção pelos pobres: na teologia da libertação e na pedagogia lassalista}

Confrontada pela realidade da pobreza, desenvolveu-se, na América Latina, a TdL situada e enraizada na práxis do trabalho pastoral. A liberdade que esses teólogos

${ }^{44}$ IPEA, 2013, p. 18.

${ }^{45}$ IPEA, 2013, p. 05.

${ }^{46}$ IPEA, 2013, p. 05.

47 IPEA, 2013, p. 15.

48 YANNOULAS, Silvia Cristina; ASSIS, Samuel Gabriel; FERREIRA, Kaline Monteiro. Educação e pobreza: limiares de um campo em (re) definição. Revista Brasileira de Educação, Rio de Janeiro, v. 17, n. 50, p. 345, 2012. 
anunciaram e continuam anunciando para os pobres é a mesma liberdade que Jesus propagou há mais de dois mil anos:

O Espírito do Senhor está sobre mim, porque me ungiu; e enviou-me para anunciar a boa nova aos pobres, para sarar os contritos de coração, para anunciar aos cativos a redenção, aos cegos a restauração da vista, para pôr em liberdade os cativos, para publicar o ano da graça do Senhor ${ }^{49}$.

Vai nesse sentido o posicionamento de Müller referente à pobreza: “A pobreza não faz bem. Pelo contrário: a pobreza, pelas tantas situações extremas e difíceis de emergências, é causa de conflitos nas famílias, nos grupos e nas comunidades" ${ }^{50}$. Para Gutiérrez, por outro lado, a

pobreza é um ato de amor e de libertação. Tem valor redentor. Se a causa última da exploração e alienação do homem é o egoísmo, a razão profunda da pobreza voluntária é o amor ao próximo. Não pode então ter sentido de pobreza cristã a não ser como compromisso de solidariedade com os pobres, com aqueles que sofrem miséria e injustiça, a fim de testemunhar o mal que estas representam, como fruto do pecado e ruptura de comunhão. Não se pode idealizar a pobreza, porém ao contrário assumi-la como é, como um mal, para protestar contra ela e esforçar-se por aboli-la ${ }^{51}$.

No desenvolvimento da TdL há uma indagação fundamental e difícil de responder: "Como podemos falar aos pobres do amor de Deus diante de tanta miséria e injustiça?" 52 . Formulação de Leonardo Boff: "Como se revela Deus em semelhante situação? [...] Que face mostra Deus dentro de nosso mundo inumano?"53. Dizemos, na teologia, que Deus se dá a conhecer a partir da história que habitamos. Mas, agora em questionamento do mesmo Boff: como vamos explicar isso para os "cinquenta milhões de brasileiros que não conseguem ter uma alimentação" 54 adequada?

Hoje a pobreza não assusta os cristãos, deixa-os, no entanto, entristecidos. Especialmente no contexto da pobreza, Jesus foi e continua sendo um pastor difícil de ser seguido fielmente porque exige dos cristãos uma posição ao lado de um povo que cada vez mais é objeto de uso, descartável em uma sociedade globalizada. É um seguimento difícil porque aceitar o Evangelho é assumir a missão que Jesus deixou aos batizados. Segundo Mesters, "numa sociedade assim, seguir Jesus para anunciar o Reino significa assumir com ele a mesma luta em defesa da vida" 55 dos excluídos e marginalizados.

49 São Lucas 4.18-19.

${ }^{50}$ MÜLLER, Gerhard Ludwig. Pobre para os pobres: a missão da Igreja. São Paulo: Paulinas, 2014. p. 147.

${ }^{51}$ GUTIÉRREZ, 1975, p. 247.

52 MÜLLER, 2014, p. 148.

53 BOFF, 2012, p. 62.

${ }^{54}$ BOFF, 2012, p. 60.

${ }_{55}$ MESTERS, 2007, p. 85. 
Para Dussel, "no sentido bíblico, 'pobre' é o termo dominado, oprimido, humilhado, instrumentalizado da relação prática que se denomina pecado" 56 . Jesus Cristo se tornou um "monstro", sendo, "assim, uma vez que Jesus representa a justiça, isso significa que a própria justiça é transgressora com respeito à ordem social do poder: Deus está do nosso lado contra as forças deste mundo"57. Segundo o papa Francisco, "Cristo se fez pobre e sempre se aproximou dos pobres e marginalizados, a preocupação pelo desenvolvimento integral dos mais abandonados da sociedade" 58 . O cristão carrega consigo o compromisso que Jesus Cristo assumiu com os pobres, um pacto que foi assumido perante Deus. Com o que podemos imaginar o quão grande e forte foi essa prova de serviço pelo Reino.

Para Gauthier e Tardif ${ }^{59}$, os Irmãos Lassalistas foram os primeiros professores leigos profissionais dedicados exclusivamente à educação, definida na segunda regra do instituto: "Não poderão ser sacerdotes, nem aspirar ao estado eclesiástico, nem mesmo cantar, revestir sobrepeliz ou exercer função alguma na Igreja, exceto ajudar Missa rezada" ${ }^{\prime 60}$. O projeto pedagógico da educação lassalista visava à educação cristã da criança oriunda de família pobre ou trabalhadora, através de um planejamento minucioso da Escola Cristã e da docência para o ensino e aprendizado da catequese, da escrita, da leitura e do cálculo em nível elementar. As práticas didáticas tinham a finalidade pragmática da emancipação pelo trabalho: "redigirão, por si mesmos, cartas, promissórias, recibos, aluguéis e contratos de trabalho e outras coisas que lhes possam ser úteis posteriormente" ${ }^{91}$. Ainda segundo Gauthier e Tardif, La Salle e os Irmãos organizaram a primeira escola normal para a formação de professores da história da pedagogia moderna. Os pobres também estão no centro desse processo formativo: os formadores de "novos mestres" devem inspirar essa "caridade perfeita e desinteressada para com o próximo. Induzi-los, mesmo, a darem maiores demonstrações externas de amizade e afeição aos pobres do que aos ricos" ${ }^{\prime \prime 2}$.

São João Batista de La Salle e seus primeiros irmãos professores de vida religiosa consagrada desenvolveram uma pedagogia e criaram uma rede de escolas gratuitas de educação elementar como uma forma de superar a pobreza, a mendicância e a precariedade da economia. Os principais beneficiados com a educação dada em suas escolas eram os filhos dos artesãos e das famílias pobres urbanas. Segundo Hengemüle, La Salle "opta preferencialmente pelos pobres, confia na capacidade destes, toma a Jesus Cristo como referencial de humanidade, pratica a continuidade permanente entre teoria e a ação" ${ }^{63}$. Há preferencialidade pelos pobres, a opção pedagógica e

${ }^{56}$ DUSSEL, Enrique. Ética comunitária. Petrópolis: Vozes, 1986. p. 33.

${ }^{57}$ ZIZEK, Slavoj; MILBANK, John. A monstruosidade de Cristo: paradoxo ou dialética? São Paulo: Três Estrelas, 2014. p. 360.

${ }^{58}$ FRANCISCO, Papa. A Igreja da Misericórdia: minha visão para a Igreja. São Paulo: Paralela, 2014. p. 25.

${ }^{59}$ GAUTHIER; TARDIF, 2010, p. 126-148.

${ }^{60}$ LA SALLE, 2012a, p. 18.

${ }^{61}$ LA SALLE, São João Batista de. Guia das Escolas Cristãs. In: Unilasalle, 2012b. v. II, p. 70.

${ }^{62}$ LA SALLE, 2012 b, v. II, p. 296.

${ }^{63}$ HENGEMÜLE, 2007, p. 61. 
teológica de São João Batista de La Salle é notável para uma sociedade aristocrática, porque "fez sua escola exercer a função social de promover os pobres" ${ }^{4}$. Assim como a TdL renovou a teologia e a pastoral latino-americana e a partir desse contexto contribuiu para a renovação da teologia e da pastoral no mundo todo, também La Salle

pode bem ser considerado um inovador incômodo, que rompe com a tradição das congregações religiosas quando decide fundar um instituto de leigos - os Irmãos das Escolas Cristãs não são padres - que se excluem, por vocação, da cultura das elites para se consagrarem às escolas de caridade destinadas aos mais pobres: eles não ensinarão o latim, mas somente os rudimentos do ler, do escrever e do contar e eles o farão em francês ${ }^{65}$.

João Batista de La Salle, Nicolas Vuyart e Gabriel Drolin a professaram no chamado "Voto Heroico" ${ }^{66}$. Diante de um instituto em declínio, eles fizeram um voto de associação e de união para, juntos, construírem uma resposta alternativa tendo em vista o serviço educativo aos pobres. "Somos Irmãos e discípulos de Jesus, seus embaixadores e ministros para representar seu poder para aqueles que vivem afastados da salvação. ${ }^{967}$ Ao exemplo de Jesus, os Irmãos sentem-se chamados a viver em relação profunda e dinâmica com as pessoas excluídas da sociedade. Experimentam Deus a partir do coração e mostram essa experiência através do serviço educativo aos pobres. Para La Salle, oferecer tal serviço exigia muito mais que caridade, além dela, é também necessário produzir uma ciência pedagógica capaz de, ao mesmo tempo, fundamentar e fundamentar-se na prática educativa na escola destinada, preferencialmente, aos filhos de artesãos e pobres urbanos:

Os Irmãos das Escolas Cristãs são na verdade os primeiros professores realmente formados para um ensino popular nas cidades. Eles inventam um material pedagógico padronizado, popularizam os grandes quadros impressos com letras e sílabas, distribuem a todos os alunos manuais idênticos, dividem a aprendizagem obedecendo a uma progressão rigorosa, organizam exames mensais dirigidos por um Irmão inspetor que decide se o aluno pode ou não passar para uma classe superior ${ }^{68}$.

Nessa perspectiva, a pedagogia de La Salle pode ser interpretada como uma pedagogia libertadora porque visava à emancipação das crianças, pois os Irmãos estavam convictos pela fé e pela experiência profissional de que recebendo uma boa edu-

${ }^{64}$ HENGEMÜLE, 2007, p. 61.

${ }_{65}$ JULIA, Dominique. A Cultura Escolar como Objeto Histórico. Revista Brasileira de História da Educação, Maringá, v. 1, n. 1, p. 9-43, 2001. p. 28.

${ }^{66}$ LA SALLE, São João Batista de. O voto heroico. In: Obras Completas. Canoas: Unilasalle, 2012c. v. I, p. 39. Nicolas Vuyart e Gabriel Drolin são os Irmãos que, com La Salle, decidiram garantir o futuro do Instituto dos Irmãos das Escolas Cristãs, sendo os primeiros a nele emitirem os votos.

${ }^{67}$ LA SALLE, São João Batista de. Meditações para o tempo de Retiro. In: Obras Completas. Canoas: Unilasalle, 2012d. v. II-B, p. 433- 483. Terceira (p. 440-442) e quarta meditação (p. 443-445).

${ }^{68}$ CHARTIER, Anne-Marie. Alfabetização e formação dos professores da escola primária. Revista Brasileira de Educação, Rio de Janeiro, n. 8, p. 6, 1998. 
cação as crianças pobres seriam "capazes de tudo"69, inclusive de superar a pobreza na sociedade aristocrática francesa do século XVII.

\section{Considerações finais}

É razoável defender para a América Latina do século XXI, tanto a teologia proposta por Gutiérrez no final do século XX, como a pedagogia centrada nos pobres proposta por La Salle no século XVII? Para responder a essa questão, o artigo analisou o surgimento da TdL no contexto social latino-americano de luta contra a pobreza nas quatro últimas décadas do século XX. Na sequência, analisou o novo contexto de enfrentamento da pobreza nas duas primeiras décadas do século XXI no Brasil, a partir da emergência de políticas públicas focadas no objetivo constitucional de "erradicar a pobreza e a marginalização e reduzir as desigualdades sociais" "70. A constatação acerca dessa mudança qualitativa na realidade da pobreza justifica a pertinência da opção pelos pobres defendida tanto pela TdL como pela pedagogia lassalista.

Apesar dos avanços democráticos nas duas primeiras décadas do novo século no Brasil, permanece a realidade da pobreza neste país e também no continente latino-americano. Assim, a TdL continua pertinente, tanto quanto uma pedagogia centrada na educação das crianças pobres. Os povos latino-americanos ainda anseiam por libertação da pobreza. Ainda anseiam por mais dignidade humana e liberdade. Sem dúvida, é no meio dos pobres que a necessidade de liberdade é mais visível e emergente. É um dos motivos, entre tantos outros, pelos quais a TdL ganha novas forças na América Latina do século XXI, porque "a teologia da libertação é resposta à problemática pastoral da Igreja, especialmente colocada no contexto latino-americano, em que a luta pela libertação constitui uma exigência fundamental do Evangelho e uma antecipação do Reino de Deus"71, tendo como ponto de partida a experiência dos pobres com Deus e a "experiência de Deus" com os pobres.

De sua parte, a TdL permite ao indivíduo pensar as atitudes missiológicas de Jesus, que se posicionou "ao lado dos excluídos" por conhecer suas necessidades. Permanece, portanto, a necessidade de a igreja colocar-se a serviço do Reino e não de si mesma. Segundo o papa Francisco, "há um sinal que nunca deve faltar: a opção pelos últimos, por aqueles que a sociedade descarta e joga fora" 72 . É dessa forma que a igreja testemunha a verdadeira graça do Evangelho. De outra parte, a pedagogia lassalista proporciona ao indivíduo a oportunidade de superar sua situação de pobreza. Isso, ela o faz mediante o desenvolvimento escolar de um aprendizado útil para a formação de um trabalhador capaz de transformar, pelo seu conhecimento e seu esforço produtivo, as condições sociais que geram a própria pobreza, ou seja, trata-se do que hoje a pedagogia denomina de finalidade emancipatória da educação, posto que a educação

${ }^{69}$ LA SALLE, 2012b, v. II, p. 197.

70 BRASIL. Constituição da República Federativa do Brasil de 1988, art. $3^{\circ}$, inciso III. Texto disponível em: $<$ http://www.planalto.gov.br/ccivil_03/Constituicao/Constituicao.htm>. Acesso em: 02 dez. 2016.

71 CATÃO, Francisco. O que é teologia da libertação. São Paulo: Nova Cultural; Brasiliense, 1986. p. 63.

${ }^{72}$ FRANCISCO, 2013, p. 161. 
básica, universal e obrigatória, visa "ao pleno desenvolvimento da pessoa, seu preparo para o exercício da cidadania e sua qualificação para o trabalho", conforme estabelece o artigo 205 da Constituição Federal de 1988, que traduz para o âmbito da política educacional um dos "objetivos fundamentais da República Federativa do Brasil", qual seja, o de "erradicar a pobreza e a marginalização" (artigo $3^{\circ}$, inciso III).$^{73}$ Tanto na França do século XVII como no Brasil do século XXI, continuamos precisando de uma escola "muito útil para os meninos pobres em sua inserção na vida social""74. Assim, um Irmão lassalista pode interpretar a opção pelos pobres como a justificação necessária tanto para a sua aspiração à vida religiosa consagrada através do Instituto dos Irmãos das Escolas Cristãs como, por consequência, para a sua formação inicial e permanente como professor no exercício de sua profissão.

\section{Referências}

ALBUQUERQUE, Francisco das Chagas de. Teologia da Libertação na pós-modernidade: contribuição à humanização. Perspectiva Teológica, Belo Horizonte, v. 48, n. 2, p. 289-316, 2016. ALDUNATE, José et al. Direitos humanos, direitos dos pobres. São Paulo: Paulinas, 1990.

BETTO, Frei. Fome de Deus. São Paulo: Paralela, 2013.

BOFF, Leonardo; BOFF, Clodovis. Como fazer Teologia da Libertação. Petrópolis: Vozes, 1986. BOFF, Leonardo. Experimentar Deus: a transparência de todas as coisas. 2. ed. Petrópolis: Vozes, 2012.

BOFF, Clodovis. A opção preferencial pelos excluídos. In: BEOZZO, José Oscar et al. Vida, clamor e esperança: reflexões para os 500 anos de evangelização a partir da América Latina. São Paulo: Loyola, 1992.

BRASIL. Constituição da República Federativa do Brasil de 1988. Brasília: Presidência da República; Casa Civil; Subchefia para Assuntos Jurídicos. Disponível em: $<$ http://www.planalto. gov.br/ccivil_03/constituicao/constituicao.htm>. Acesso em: 13 jun. 2017.

CATÃO, Francisco. O que é teologia da libertação. São Paulo: Nova Cultural; Brasiliense, 1986. CHARTIER, Anne-Marie. Alfabetização e formação dos professores da escola primária. Revista Brasileira de Educação, Rio de Janeiro, n. 8, p. 4-12, 1998.

CRESPO, Antônio Pedro Albernaz; GUROVITZ, Elaine. A pobreza como um fenômeno multidimensional. RAE-eletrônica, São Paulo, v. 1, n. 2, p. 1-12, 2002.

DOCUMENTO de Puebla. Texto Oficial Puebla de Los Angeles, México, 27-1 a 13-2 de 1979. São Paulo: Paulinas. Disponível em: <http://www.pucminas.br/imagedb/documento/ DOC_DSC_NOME_ARQUI20130906182452.pdf?PHPSESSID=6fa1b33e3b82de1acf51b1d b1e7654e7>. Acesso em: 30 out. 2015.

DUSSEL, Enrique. Ética comunitária. Petrópolis: Vozes, 1986.

FRANCISCO, Papa. A Igreja da Misericórdia: minha visão para a Igreja. São Paulo: Paralela, 2014.

FRANCISCO, Papa. Exortação Apostólica Evangelli Gaudium. São Paulo: Paulinas, 2013.

${ }^{73}$ BRASIL. Constituição da República Federativa do Brasil de 1988. Brasília: Presidência da República; Casa Civil; Subchefia para Assuntos Jurídicos.

${ }^{74}$ TAGLIAVINI, João Virgílio; PIANTKOSKI, Marcelo Adriano. João Batista de La Salle (1651-1719): um silêncio eloquente em torno do educador católico que modelou a escola moderna. Revista HISTEDBR On-line, Campinas, n. 53, p. 16-40, 2013. p. 22. 
GAUTHIER, Clermont; TARDIF, Maurice. A Pedagogia: teorias e práticas da Antiguidade aos nossos dias. Petrópolis: Vozes, 2010.

GUTIÉRREZ, Gustavo. Teologia da libertação: Perspectivas. São Paulo: Loyola, 2000.

GUTIÉRREZ, Gustavo. MÜLLER, Gerhard Ludwig. Ao lado dos pobres: Teologia da Libertação.

São Paulo: Paulinas, 2014.

GUTIÉRREZ, Gustavo. A força histórica dos pobres. Petrópolis: Vozes, 1981. Teologia da Libertação: perspectivas. Petrópolis: Vozes, 1975.

HENGEMÜLE, Edgard. Educação Lassaliana: Que Educação? Canoas: Unilasalle, 2007.

IPEA. Instituto de Pesquisa Econômica Aplicada. Duas décadas de desigualdade e pobreza no Brasil medidas pela Pnad/IBGE. Comunicados do Ipea, Brasília, n. 159, 01 de outubro de 2013. Disponível em: <http://www.ipea.gov.br/portal/images/stories/PDFs/comunicado/131001_comunicado159.pdf $>$. Acesso em: 21 set. 2015.

JULIA, Dominique. A Cultura Escolar como Objeto Histórico. Revista Brasileira de História da Educação, Maringá/PR, n. 1, p. 9-43, 2001.

LA SALLE, São João Batista de. Regras Comuns dos Irmãos das Escolas Cristãs. In:

Obras Completas. Canoas: Unilasalle, 2012. v. II-A, p. 18-86.

LA SALLE, São João Batista de. Guia das Escolas Cristãs. In: Unilasalle, 2012b. v. III, p. 19-317.

LA SALLE, São João Batista de. O voto heroico. In: . Obras Completas. Canoas: lasalle, 2012c. v. I, p. 39.

LA SALLE, São João Batista de. Meditações para o tempo de Retiro. In: . Obras Completas. Canoas: Unipletas. Canoas: Unilasalle, 2012d. v. II-B, p. 433- 483.

LEUBET, Ângelo Ezequiel; PAULY, Evaldo Luis; SILVA, Valdir Leonardo da. Contribuições de João Batista de La Salle para a constituição da escola moderna. Revista Brasileira de História da Educação, Maringá-PR, v. 16, n. 4 [43], p. 32-63, 2016.

LÖWY, Michael. Guerra dos deuses: religião e política na América Latina. Petrópolis: Vozes, 2000.

MESTERS, Carlos. Com Jesus na contramão. São Paulo: Paulinas, 2007.

MÜLLER, Gerhard Ludwig. Pobre para os pobres a missão da Igreja. São Paulo: Paulinas, 2014. MUÑOZ LEÓN, Diego A. Cómo los lasalianos comprenden la asociación desde su experiencia personal: estudio de testimonios de hermanos y laicos de la RELAL. Revista Digital de Investigación Lasaliana, Roma, n. 1, p. 51-64, 2010.

NORT, Egon. Brasil rumo ao primeiro mundo. Florianópolis: Edição do autor, 1997. PRZEWORSKI, Adam. A mecânica da instabilidade de regime na América Latina. Novos Estudos - CEBRAP, São Paulo, v. 100, p. 27-54, 2014.

SUSIN, Luiz Carlos (Org.). Teologia para outro mundo possível. São Paulo: Paulinas, 2006.

TAGLIAVINI, João Virgílio; PIANTKOSKI, Marcelo Adriano. João Batista de La Salle (1651-1719): um silêncio eloquente em torno do educador católico que modelou a escola moderna. Revista HISTEDBR On-line, Campinas, n. 53, p. 16-40, 2013.

YANNOULAS, Silvia Cristina; ASSIS, Samuel Gabriel; FERREIRA, Kaline Monteiro. Educação e pobreza: limiares de um campo em (re) definição. Revista Brasileira de Educação, Rio de Janeiro, v. 17, n. 50, p. 329-351, 2012.

ZIZEK, Slavoj; MILBANK, John. A monstruosidade de Cristo: paradoxo ou dialética? São Paulo: Três Estrelas, 2014. 